\title{
40 anos da pós-graduação da EEFE-USP aos olhos do primeiro doutor
}

Agradecendo o honroso convite para elaborar um manuscrito para compor este número especial da RBEFE comemorativo dos 40 anos do programa de pós-graduação "stricto-sensu" da Escola de Educação Física e Esporte da Universidade de Sáo Paulo e ciente da enorme responsabilidade que se associa à honra a mim conferida, procurarei abordar o tema definido pelos editores " 40 anos da pós-graduação da EEFE-USP aos olhos do primeiro doutor", mediante um roteiro em forma de sinopse de quatro questóes, em meu entendimento, fortemente relacionado ao sucesso passado, presente e futuro deste importante programa de pós-graduação.

Para tanto, em um primeiro momento, inicio com um tópico introdutório que procura pontuar a efetivamente do programa na formação em nível de pós-graduação de profissionais vinculados à área de conhecimento denominada no contexto brasileiro de educação física e esporte. Seguindo nesta direção, em um segundo momento, considerando que se trata de um programa de formação "stricto-sensu" na área, julgo necessário resgatar aspecto específico de uma discussão histórica sobre a caracterização acadêmica e profissional da educação física. $\mathrm{O}$ terceiro tópico abordado refere-se ao formato atualmente considerado para os programas de pós-graduaçáo. E, por último, tendo em vista o estágio avançado de consolidação deste programa de "stricto-sensu" e da liderança que exerce na pós-graduação brasileira, tentei estabelecer uma provocação para a necessidade de implantação de cursos de mestrado profissional.

\section{Proposição e evolução do programa "stricto sensu" da EEFE-USP}

Pioneiro na America Latina, o programa de pósgraduação da EEFE-USP iniciou suas açôes em março de 1977, com a oferta do curso de mestrado em educação física, com intuito principal de contribuir na formação de docentes para atuar no ensino universitário e qualificar os pós-graduandos para desenvolver pesquisa na área de formação ${ }^{1}$. A partir de então, a educaçáo física brasileira e por extensão, a educação física latino-americana, passou a dispor de um curso "stricto sensu" destinado ao aperfeiçoamento de graduados no segmento de ensino e pesquisa, contribuindo, dessa maneira, fortemente para a evolução do conhecimento na área.

$\mathrm{Na}$ sequência, no inicio do ano letivo 1990, o programa da EEFE-USP ampliou seu foco de atuação e acolheu os primeiros pós-graduandos para o recém-criado curso de doutorado em educaçáo física. Com essa iniciativa se igualou aos programas de pósgraduaçáo de grande destaque nas demais áreas de conhecimento, oportunizando a formaçáo nos graus acadêmicos de mestre e doutor em educaçáo física ${ }^{2}$.
Ao longo de sua existência, de acordo com a demanda e a necessidade de atualização, o programa de pós-graduação da EEFE-USP passou por constantes reformulaçóes. Contudo, reestruturação importante ocorreu em 2013 ao contemplar o esporte como uma área específica de conhecimento. Neste contexto, passou a receber a denominação de Programa de Pós-graduação em Educação Física e Esporte, com duas áreas de concentração: "Estudos Biodinâmicos da Educação Física e Esporte" e "Estudos Socioculturais e Comportamentais da Educação Física e Esporte”.

Seguramente, nessas quatro décadas de existência, o programa de pós-graduação da EEFE-USP vem contribuindo de forma expressiva para o desenvolvimento do conhecimento e da intervenção no meio acadêmico nas áreas de educação física e esporte, mediante o aperfeiçoamento competente de pesquisadores e docentes em nível de pósgraduação. Evidência de sua efetividade no Sistema Nacional de Pós-Graduação é traduzida pelas 
avaliaçôes periódicas realizadas pelo Comitê de Especialistas da CAPES/MEC (Coordenadoria de Aperfeiçoamento de Pessoal de Ensino Superior/ Ministério da Educação). Neste particular, desde a sua implantação tem recebido distinção e reconhecimento de excelência. No momento, sustenta a mais elevada pontuação na escala de medida de qualidade atribuída aos programas "stricto sensu" no Brasil (conceito equivalente a 7), pontuação atribuída exclusivamente aos programas de elevado grau de internacionalização mediante parcerias acadêmicas e científicas com instituiçóes de elevada repercussão em seus países ${ }^{3}$.

Em razão da sólida formação oferecida aos pósgraduandos, os egressos vêm assumindo funçôes de destaque em suas universidades de origem e em órgãos gestores no campo acadêmico e científico; além do que, as pesquisas que deram origem a elaboração de dissertaçóes e teses vêm sendo disseminadas em periódicos de elevado impacto nacional e internacional, o que demonstra sua efetiva contribuiçáo para o avanço do conhecimento na área. Considerando que proporção significativa dos pós-graduandos do programa da EEFE-USP procede de diferentes regióes brasileiras e de outros países, destaca-se, também, o papel multiplicador dos egressos na idealização, na proposição e na atuação em outros programas "stricto sensu", contribuindo decisivamente para a concretização das áreas de educação física e esporte.

No entanto, a despeito de todo sucesso alcançado ao longo dos 40 anos de sua trajetória, os desafios que se colocam no presente para um programa "stricto sensu” de excelência nas áreas de educação física e esporte, como é o caso do programa de pós-graduação da EEFE-USP, são imensos. Na sequência, tomo a liberdade de apresentar três questôes que julgo de fundamental importância para o momento.

\section{Caracterização acadêmica e profissional da educação física}

Sem a pretensão de alcançar uma delimitação para o universo de conhecimento tratado na educaçáo física e, por sua vez, definir seu campo de atuaçáo profissional, acredito que, para um programa de pós-graduaçáo táo bem consolidado nacional e internacionalmente, seria útil realizar mais algum investimento no sentido de encaminhar uma tentativa de caracterização acadêmica e profissional mais clara para a denominada área de educação física.

Em momentos anteriores, sobretudo nas décadas de 1980 e 1990, acompanhando iniciativas de estudiosos espalhados em todo o mundo, grupos de estudo e pesquisa vinculados às universidades brasileiras investiram fortemente nesta temática ${ }^{4-5}$. Contudo, talvez, na época, a menor maturidade da área de educação física no meio universitário e a formação em "stricto sensu" dos líderes dos grupos de estudo e pesquisa estar distante da área específica de educação física tenha contribuído para que o avanço alcançado náo tenha sido suficiente para uma caracterização acadêmica e profissional que atenda as exigências para consolidação de uma área específica de formação e atuação no mercado de trabalho.

Indiscutivelmente, nos últimos tempos, a educação física vem atingindo maturidade acadêmica suficiente que a credencia como uma das principais áreas de conhecimento no meio universitário.
Também, nos dias atuais, a educação física brasileira já dispóe de quantidade importante de pesquisadores e docentes com formação em "stricto sensu" na própria área, o que permite transitar por um rol de conhecimento mais específico. Destacase que, muito dessa extraordinária evolução deva ser atribuída ao pioneirismo e à liderança que o programa de pós-graduação da EEFE-USP exerce atualmente na educação física de nosso país.

Julgo que as fragilidades associadas à caracterização acadêmica e profissional da educação física vão desde consideraçôes etimológicas de sua denominação até atribuiçóes e expectativas laborais que lhe são atribuídas. Neste particular, a definição de uma denominação acadêmica deve tornar-se explícita por si só em sua análise científica, assim como os conceitos e os princípios norteadores na atuação profissional devem ser empregados de maneira adequada e coerente com sua atribuição na sociedade.

De imediato, um sério obstáculo para a educação física inicia com a falta de unidade de critérios em sua concepção etimológica. Educação física constituise em uma expressão polissêmica de conteúdo semântico variável e pouco definido. Portanto, tem comportado concepçóes e interpretaçóes distintas de acordo com mençôes de época, lugar e contexto de referência. Ao longo da história, a educação 
física já foi ou vem sendo tratada mediante diversas outras nomenclaturas, como é o caso de educação motora, educação corporal, cultura física, cultura corporal, educação esportiva, ciência do movimento humano, ciência da motricidade, entre outras. Mais recentemente, por solicitação do mercado de trabalho e de regulamentação da profissão, por vezes, a educação física é confundida com atividade física, exercício físico, ginástica, dança, esporte, etc. Frequentemente, em documentos acadêmicos e de normatização da atuação profissional constam direcionamentos do tipo "fazer educação física", em analogia a prática de exercício físico, esporte, etc.

A concepção de educação tem um sentido amplo e complexo para que possa denominar especificamente uma área acadêmica ou profissional. A única área de conhecimento e atuação profissional que utiliza o termo educação em sua denominação é a educação física. Etimologicamente, o termo educação pode estar associado a dois enfoques. Uma das significaçóes provém do vocábulo latino "educare", que significa criar, alimentar, entendido como um processo aportado pelo educador para o educando, ou seja, o estímulo é exclusivamente extrínseco e o educando o recebe de maneira passiva. A segunda significação, também proveniente da raiz latina "educere", significa sacar para fora, ou seja, considera a educação como uma estimulação daquilo que o educando já se apropriou. Neste caso, o educador é o guia ou o condutor, enquanto o educando é o que se forma com responsabilidade individual ${ }^{6}$.

Uma vez abordado o termo educação, sigo com a análise do segundo componente da expressão educação física. A atual significação do termo física/físico vem do grego "fysis", um dos conceitos de mais ampla evolução no mundo da Grécia Antiga que significa a natureza, e na interpretação grega física/físico como pertencente ao mundo natural: o corpo; em contraposição a alma, o sobrenatural e o espiritual. Atualmente, em um significado amplo, física/físico é o que pertence a constituição e a natureza do corpo humano ${ }^{6}$.

Com este encaminhamento etimológico e reconhecendo as concepçóes dos termos educação e física/físico, parece lógico que a educação física deva expressar a abordagem de açóes direcionadas à conservação e ao aprimoramento das estruturas do corpo humano, ou seja, claramente direcionada à promoção e à educação em saúde. Neste sentido, deve-se destacar que, conservação e aprimoramento das estruturas do corpo humano entendido mediante concepçôes de promoção e educação em saúde, não depende exclusivamente da dotação biológica, mas também e principalmente, dos hábitos e modos de viver.

A atual concepção considerada pelos programas brasileiros de pós-graduação "stricto sensu" assume excessiva pluralidade e pretensão de abrangência para a educação física, transitando de temas vinculados ao desenvolvimento motor em lactantes aos efeitos de esforço físico associado ao uso de alguma droga nos sistemas orgânico, passando por conceitos ergonômicos de design de calçados e equipamentos. Logo, uma sobrecarga e diversidade de temas e assuntos tratados em seu espectro que suscita dificuldade para definição de sua área acadêmica, diminui seu profissionalismo e ameaça sua existência futura.

Logo, a provocação que lanço para reflexão é tratar a área de conhecimento e a atuação profissional da educação física em um sentido absolutamente mais restrito, se não referenciada unicamente a disciplina do currículo de escolarização. Contudo, nesta direção, abrigando não apenas temas tradicionalmente vinculados ao comportamento motor, mas também, outros tipos de comportamentos de proteção e de risco para a saúde: alimentação, uso de substâncias, repouso suficiente, controle de estresse, sexualidade/ anticoncepção, auto estima/autoconceito, controle de riscos, adaptação/confrontação, etc.

\section{Estrutura organizacional dos cursos de mestrado e doutorado}

Em minha leitura, mais recentemente, alguns programas de pós-graduação vêm sofrendo forte pressão na tentativa de abreviar a sequência de formação "stricto sensu". Trata-se de permitir o acesso de pós-graduandos aos cursos de doutorando sem que esses tenham vivenciado a experiência dos cursos de mestrado, sob a alegação de que, para aqueles pós-graduandos que pretendem dar sequência a sua formação em nível de doutorado, os mestrados tornaram-se um curso sem muita justificativa em si mesmo.

O modelo dos programas de pós-graduação "stricto sensu" no Brasil acompanhou a experiência norte-americana, centrado em dois níveis 
hierarquizados, mestrado e doutorado, sem que o primeiro seja requisito indispensável para o segundo, ou seja, neste caso, o mestrado pode ser considerado etapa preliminar para a obtenção do grau de doutor, ou como grau dispensável admitindo-se a possibilidade de acesso direto no nível de doutorado. Em ambos os níveis compreende estudo de um conjunto de ementas relativas ao campo específico de conhecimento selecionado pelo pós-graduando (área de concentração) e ao campo de conhecimento correlato e complementar (domínio conexo). Os programas de pós-graduação deve se completar com a preparação e a apresentação pública de um trabalho de conclusão resultante de pesquisa, dissertação, no caso de mestrado, e tese, no caso de doutorado, prevendo inclusive a figura de um docente-orientador com a incumbência de assistir e acompanhar o pós-graduando.

Contudo, se a estrutura organizacional se inspirou no modelo norte-americano, o espírito com que vem se tratando os programas de pós-graduação é em grande parte influenciado pela experiência de países europeus. Interessante destacar que nos Estados Unidos prevalece na escola básica o objetivo prioritário de socialização dos jovens, justificado pelo discurso de incentivo à autonomia e à iniciativa dos educandos, deixando para um plano secundário o domínio de conhecimentos sistematizados. Em contrapartida, na universidade os graduandos tendem a ser colocados diante de uma organização bastante bem definida que implica em tarefas de orientação e direção exercidas pelos docentes. Inversamente, nos países europeus os sistemas de escolarização básica são organizados sob a égide da concepção tradicional que coloca como objetivo principal o domínio de conhecimentos sistematizados. Em consequência, a expectativa é que os educandos ingressem no sistema universitário com um grau de maturidade e automina intelectual que possa dispensar, por parte dos docentes, uma direção e orientação mais direta dos trabalhos acadêmicos. E, especificamente nos programas de pós-graduação, sobretudo no caso do doutorado, espera-se que o pós-graduando conceba e realiza por si mesmo o próprio trabalho de conclusão do curso, sendo o docente-orientador mais um examinador e presidente da banca examinadora que alguém que dirige e interfere diretamente na definição e no desenvolvimento do tema do estudo. Assim, enquanto a experiência norte-americana impõe certa ênfase no aspecto técnico-operativo, a experiência dos países europeus a ênfase principal recai sobre o aspecto teórico.
Considerando o peso da influência europeia nos programas de pós-graduaçáo brasileiros, esse dado torna-se importante para entender a tendência que prevalece no momento. Com efeito, especificamente no caso dos cursos de mestrado, embora os pósgraduandos devem cursar determinadas disciplinas, algumas de caráter obrigatório, via de regra, os docentes-orientadores supóe razoável grau de autonomia dos mestrandos acreditando que esses definam o próprio objeto de investigação e, ato continuo, escolhem o docente-orientador adequado para acompanhar seu trabalho de conclusão do curso. Em parte este fato explica o longo tempo destinado à conclusão do mestrado associado à expectativa de que os mestrandos devem produzir um trabalho de conclusão de curso de fôlego, por vezes, equivalentes a uma tese de doutorado.

Décadas atrás esta situação não causou grandes problemas, até porque, diante da demanda reprimida para os cursos de mestrados e não existindo ainda os cursos de doutorado na área, acediam aos cursos de mestrado docentes universitários já com razoável maturidade acadêmica e uma boa experiência no magistério superior. No momento, porém, constatase que, em escala cada vez mais elevada, enquanto o docente-orientador espera que o próprio mestrando selecione de modo autônomo o tema de sua dissertaçáo, formule o problema, defina o enfoque teórico, delimite o objeto e estabeleça a metodologia e os respectivos procedimentos de análise, o mestrando sente-se sem rumo e despende muito tempo sem corresponder as expectativas do docente-orientador.

Diante desse quadro é que surge pressão para redução do tempo com tendência a secundarizar os cursos de mestrados ou, mesmo, eliminar essa etapa da pós-graduação "stricto sensu". Entendo que esse encaminhamento pode pôr em risco a qualidade dos programas de pós-graduação na área de educaçáo física e esporte, qualidade esta que advém da fusão de uma estrutura organizacional bastante articulada, derivada da influência norteamericana, e o empenho em se garantir um grau satisfatório de densidade teórica, decorrente da influência dos países europeus. Para evitar o risco apontado, preservando a particularidade da experiência brasileira, cumpre manter presente a especificidade da pós-graduação "stricto sensu", ou seja, formar pesquisadores. Neste particular, se o objetivo precípuo da pós-graduação "stricto sensu" é a formação de pesquisadores, o elemento central de sua organização é a pesquisa. E, como a pósgraduação "stricto sensu" está organizada em dois 
níveis, mestrado e doutorado, pressupóe-se que o primeiro nível tem sentido de iniciação a formação do pesquisador, reservando-se ao segundo nível a função de consolidação.

Embora seja desejável que a iniciação científica se dê na graduação, não parece razoável inscrevêla como uma exigência obrigatória nessa primeira etapa do ensino superior. Isto não apenas por razóes conjunturais derivadas das conhecidas deficiências do ensino superior, mas também por razôes estruturais. Com efeito, o vetor principal dos cursos de graduação é a formação para o mercado de trabalho, e não a formação de pesquisadores. Por outro lado, mesmo que se alcançasse uma difusão bastante ampla da chamada iniciação científica nos cursos de graduação, é lícito supor que sua tarefa não se ligaria diretamente ao objetivo de formar pesquisadores, mas sim de familiarizar o graduando com processos e procedimentos de investigação científica, o que não implicaria necessariamente na realizaçáo de projetos próprios e completos de investigaçáo.

Por sua vez, no caso do curso de mestrado, a iniciação requerida é realizada mediante a elaboração de um trabalho completo de investigação. De fato, para a maioria dos mestrandos este é o primeiro trabalho de pesquisa que se cumpre, abarcando todas as etapas implicadas no tipo de investigação considerada. Portanto, cabe ao mestrando, com auxílio do docente-orientador, realizar a escolha do tema, a formulaçáo do problema, a delimitação do objeto e o estabelecimento da metodologia e respectivos procedimentos de análise, redigindo, em consequência, o texto correspondente com uma estrutura lógica adequada à compreensão plena do assunto tratado.

O texto referido constitui no que se convencionou denominar de dissertação de mestrado. De fato, dissertar significa discorrer, expor, abordar determinado assunto. Distingue-se da tese, denominação reservada ao trabalho de doutorado, já que tese significa posiçấo, sugerindo que a defesa de uma tese é a defesa de uma posição diante de determinado problema. A tese pressupóe os requisitos de autonomia intelectual e de originalidade, já que estas são condiçóes para que alguém possa expressar uma posição própria sobre determinado assunto. Tais requisitos não são necessariamente exigidos no caso da dissertação de mestrado. Supõe-se que é a conclusão do mestrado que propiciará o preenchimento desses requisitos, uma vêz que, tendo realizado com apoio do docente-orientador um trabalho completo de investigação, esse exercício de pesquisa lhe permite adquirir domínio teórico e prático do processo, atingindo, dessa forma, a desejada autonomia intelectual que lhe facultará a formulação original de novos objetos de investigação. Dessa forma, enquanto para o curso de mestrado a autonomia intelectual e a originalidade constituem ponto de chegada, um resultado, para o doutorado esses requisitos se póem no ponto de partida como condiçóes prévias para a realização da etapa final do processo de formaçáo de pesquisador, levado a cabo pelos programas de pósgraduação "stricto sensu".

À vista do exposto, entendo que pretender a redução do tempo de formaçáo de pós-graduação "stricto sensu" abrindo máo do curso de mestrado é obter a redução ao preço de sua descaracterização. $\mathrm{E}$, desde que, o ponto central e o momento culminante do curso de mestrado estão configurados na elaboração da dissertação, ao invés de eliminar a etapa de mestrado, a sugestão é repensar sobre o atual formato de elaboraçáo das dissertaçóes de mestrado. Neste particular, a proposta é pensar as dissertaçóes incidindo sobre temas relevantes ainda náo suficientemente explorados, cabendo ao mestrando a tarefa de realizar levantamento bibliográfico, o mais completo possível, de informaçóes disponíveis na literatura, organizá-las de acordo com critérios lógicos-metodológicos adequados e redigir o texto correspondente que permita o acesso ágil ao assunto tratado. A existência dessas dissertaçóes possibilitaria aos estudantes de doutorado e aos demais pesquisadores realizar, a partir de informaçóes primárias devidamente organizadas, sínteses de amplo alcance.

A proposta supóe que os docentes-orientadores dos cursos de mestrado identifiquem os temas, os enfoques e os momentos da educação física brasileira que se encontram de certo modo em aberto nas diferentes áreas do conhecimento, estabelecendo um amplo programa de produçáo de material em que seriam engajados os estudantes de mestrado para elaboração das respectivas dissertaçóes, com o que, ao mesmo tempo que se iniciam na condição de pesquisador, estão oferecendo uma contribuição significativa para o avanço do conhecimento na área.

Não obstante, a estratégia da produção sistemática de textos de base em cada programa de pós-graduação "strito sensu" parece ser uma forma simples e fecunda de assegurar, para a maioria dos pós-graduandos que ingressam nos cursos de mestrado, a iniciação de sua formação como pesquisador já que oferece alternativas precisas para a elaboraçáo das respectivas dissertações, poupando-lhes tempo e energia ao 
envolvê-los de imediato em um processo real de investigação. Concluída com êxito essa etapa de iniciação, no doutorado pode-se concentrar fortemente na elaboração da investigação de campo. Equacionando-se de maneira adequada a questão de organização dos estudos que articule as duas etapas de formação de pesquisadores, a de iniciação (mestrado) e a de consolidação (doutorado), torna-se possível preservar e, mesmo, aprofundar e fortalecer a experiência da pós-graduação de educação física e esporte no Brasil que, fundindo a estrutura organizacional do modelo norteamericano com a densidade teórica resultante da influência de países europeus, acabou por produzir um modelo alternativo, de certo, em alguns casos, superior àqueles que lhe deram origem.

\section{Mestrado acadêmico "versus" mestrado profissional}

A educação física e o esporte são áreas de atuação profissional; logo, seus profissionais deverão atuar também em mercados não-acadêmicos. Neste particular, dados têm mostrado que elevada proporção de egressos dos cursos de mestrado acadêmico estão atuando em empresas, em escolas de ensino básico, em clubes de "fitness", em equipes de esporte, ou como profissionais liberais. Portanto, preparados para atuar no setor acadêmico; porém, atuando fora do mercado acadêmico. Contudo, o sistema brasileiro de pós-graduação "stricto sensu" oferece um único curso de mestrado profissional na área de educação física. Trata-se do curso de mestrado profissional em Exercício Físico na Promoção da Saúde, ofertado pela Universidade Norte do Paraná. A título de comparação com outras áreas que apresenta alguma aproximação com a educação física e o esporte, a área de educação e ensino oferecem 99 opçóes de cursos de mestrado profissional, enquanto a área de saúde 102 cursos de mestrado profissional? .

A modalidade de mestrado profissional tem a finalidade de atender as necessidades dos profissionais que buscam aprimorar sua qualificação profissional, mas não planejam dedicar-se integralmente à carreira acadêmica ou a pesquisa. Conceitualmente, o mestrado profissional é similar ao mestrado acadêmico; porém, o objetivo e a forma de condução do curso são direcionados ao estudo de técnicas, processos e temáticas que venham atender demandas do mercado de trabalho. Consequentemente, os cursos de mestrado profissional apresentam uma estrutura curricular que procura enfatizar a articulação entre conhecimento atualizado, domínio de metodologias pertinentes e aplicação orientanda para o campo de atuação profissional específico. Portanto, neste caso, o quadro de docentes-orientadores deve ser constituído por profissionais qualificados para atuarem no segmento de pós-graduação "stricto sensu" e, necessariamente, voltado para o mercado de trabalho no campo específico ao do curso de mestrado profissional em questão. No que se refere à elaboração do trabalho de conclusão do curso, este é sempre vinculado a problemas reais do ambiente de trabalho e, de acordo com a natureza da área e a proposta do curso, pode ser apresentado em diversos formatos ${ }^{8}$.

Em termos de certificação, o mestrado profissional, mesmo respondendo a uma necessidade de capacitação profissional de natureza diferente da propiciada pelo mestrado acadêmico, confere idênticos grau e prerrogativas, inclusive para o exercício de docência. Logo, para preservar a qualidade dos cursos de mestrado profissional, o Ministério da Educação por intermédio da CAPES propóe critérios operacionais e normas que possam dirigir e controlar sua implantação e desenvolvimento. No entanto, em razão das especificidades dos cursos de mestrado profissional, seu acompanhamento e avaliação são realizados com base em critérios diferenciados daqueles propostos para os cursos de mestrado acadêmico.

Quanto às principais diferenças que são identificadas na proposição dos cursos de mestrado profissional e mestrado acadêmico, de imediato constata-se que os cursos de mestrado profissional são formatados para tratar especificamente de um tema pontual de atuação no mercado de trabalho. Em contrapartida, os cursos de mestrado acadêmico são formatados para tratar universo mais amplo e diversificado de conhecimento, por vezes, com abrangência equivalente à própria área de formação inicial (graduação). Por exemplo, no caso da educação física e do esporte, os cursos de mestrado acadêmico procuram abranger áreas de conhecimento tão amplas quanto às Ciências da 
Atividade Física, às Ciências da Motricidade, às Ciências do Movimento Humano, às Ciências do Esporte e, a maioria dos cursos, à Educação Física; enquanto, por exemplo, o curso de mestrado profissional abrange tema específico vinculado ao Exercício Físico na Promoção da Saúde.

O perfil dos pós-graduandos é outra importante diferença observada entre os dois cursos de mestrado. Se, por um lado, a presença de recém-egressos dos cursos de graduação é uma tendência natural nos cursos de mestrado acadêmico; por outro, nos cursos de mestrado profissional o contingente de pós-graduandos é majoritariamente constituído por profissionais já com alguma experiência de atuação no mercado de trabalho. Ainda, a formação dos pós-graduandos que optam pelos cursos de mestrado profissional ocorre fundamentalmente em serviço, considerando que a expectativa é de que estes não se afastem do ambiente de trabalho durante o curso. A formação dos pós-graduandos envolvidos nos cursos de mestrado acadêmico ocorre predominantemente no âmbito da Universidade, em situação de sala-deaula e laboratório.

O caráter do trabalho de conclusão de curso no mestrado acadêmico é exclusivamente o de um relatório de pesquisa, costumeiramente apresentado na forma de dissertação ou de artigo científico, enquanto o curso de mestrado profissional requer que se encontre naquele trabalho uma proposta de ação profissional que possa apresentar de imediato algum impacto no ambiente de trabalho de atuação do pós-graduando. Neste particular, em tese, os cursos de mestrado acadêmico têm por finalidade encaminhar a preparação de futuros pesquisadores; portanto, seus egressos tendem a continuar a carreira acadêmica nos cursos de doutorado. No caso dos cursos de mestrado profissional, o que se pretende é inserir o profissional pós-graduando na pesquisa com intenção de que retorne ao mercado de trabalho mais qualificado. Assim, de acordo com a legislação vigente, os concluintes dos cursos de mestrado profissional podem, eventualmente, candidatar-se aos cursos de doutorado; contudo, não consta na estrutura curricular desse curso de pós-graduação a preparação para um subsequente acesso aos cursos de doutorado.

Os cursos de mestrado profissional em educação física e esporte poderão contribuir na tentativa de suprimir importante lacuna existente na área, configurada pela cisão entre a prática profissional e o conhecimento acadêmico observada nos atuais programas de pós-graduação "stricto sensu" em nosso país. A proposição de cursos de mestrado profissional deverá suscitar reflexóes sobre a apropriação e a aplicação do universo de conhecimento acadêmico atualmente tratado na educação física e no esporte e a necessidade de construir novos conhecimentos, advindos fundamentalmente do exercício profissional que venha aproximar a pesquisa científica do ambiente de trabalho.

A aplicação direta e imediata do conhecimento científico na prática profissional permite que profissionais de qualquer área de atuação sejam usuários do método científico para tomada de decisóes e subsidiar transformaçóes e inovações necessárias à qualificação dos serviços oferecidos à sociedade. Particularmente o profissional de educação física, ao aliar o conhecimento científico construído e vivenciado nos cursos de mestrado profissional ao seu cotidiano de trabalho, aumenta a possibilidade de comprometimento com intervençóes mais competentes e seguras voltadas à resolução de problemas.

Por outro lado, diferentemente do que ocorre em países que dispóe de programas de pós-graduação "stricto sensu" mais bem consolidados, o Brasil não apresenta maior experiência em fomentar cursos de mestrado profissional. Vários motivos podem justificar a escassez de oferta de cursos de mestrado profissional no país, com destaque para o distanciamento identificado entre os programas de pós-graduação e o mercado de trabalho. Historicamente, os programas de pós-graduação "stricto sensu" no Brasil tem procurado enfatizar com elevada predominância a formação e a qualificação de professores universitários e pesquisadores. Neste contexto, procura-se atribuir a qualificação de profissionais para atuar no mercado de trabalho aos cursos de pós-graduação "lato sensu", também denominados de cursos de especialização.

Talvez, um dos equívocos mais acentuado observado na pós-graduação brasileira seja assumir a qualificação de profissionais para o mercado de trabalho exclusivamente mediante cursos "lato sensu”. Os chamados cursos de especialização têm por objetivo aprofundar conhecimento de tema específico do setor de atuação, procurando instrumentalizar o profissional para o domínio de determinada técnica de intervenção. Portanto, em razão de sua especificidade e do caráter de domínio técnico de sua proposta, não abrange de maneira mais ampla a área de conhecimento, tão pouco trata de maneira mais efetiva o conhecimento científico. Logo, com a necessidade de agregar cada vez mais acentuadamente o conhecimento científico na 
atuação do profissional que se encontra no mercado de trabalho, torna-se bastante temerário atribuir sua qualificação de pós-graduação apenas aos cursos "lato sensu". Neste contexto, meta principal do mestrado profissional é produzir conhecimento científico mais estreitamente relacionado ao mercado de trabalho.

\title{
Últimas palavras
}

Ao parabenizar a Escola de Educação Física e Esporte pelos 40 anos do seu programa de pósgraduação "stricto sensu", do qual fui testemunha do surgimento do curso de doutorado, e considerando o estágio avançado de crescimento e consolidação deste programa e da liderança que exerce na pós-graduação brasileira de educação física e esporte, sugiro que, entre outras questóes, as questóes aqui abordadas possam ter espaço na agenda de compromissos direcionada à constante busca de excelência. Muitíssimo grato pelo privilégio e Vida Eterna ao programa de pós-graduação da EEFE-USP !!!

\section{Referências}

1. Amadio AC. Trajetória da pós-graduação stricto sensu na Escola de Educação Física e Esporte da Universidade de São Paulo após 25 anos de produção acadêmica. Rev Bras Ciênc Esporte. 2003;24:27-47.

2. Amadio AC. Consolidação da pós-graduação stricto sensu da Escola de Educação Física e Esporte da Universidade de São Paulo: trajetória acadêmica após 30 anos de produção. Rev Bras Educ Fís Esporte. 2007;21(N esp):25-36.

3. Coordenadoria de Aperfeiçoamento de Pessoal de Ensino Superior. Brasília: CAPES. [citado 28 abr. 2017]. Disponível em: http://www.avaliacaotrienal2013.capes.gov.br/.

4. Darido SC. Apresentação e análise das principais abordagens da educação física escolar. Rev Bras Ciênc Esporte. 1998;20:58-66.

5. Mariz de Oliveira JG. Educação física escolar: construindo castelos de areia. Rev Paul Educ Fís. 1991;5:5-11.

6. Lumpkin A. Introduction to physical education, exercise science, and sport studies. 6th ed. New York:McGraw Hill; 2004.

7. Coordenadoria de Aperfeiçoamento de Pessoal de Ensino Superior. Brasília: CAPES. [citado 28 abr. 2017]. Disponível em: https://sucupira.capes.gov.br/sucupira/public/informacoes_programa/informacoesPrograma.jsf.

8. Brasil. Ministério da Educação. Portaria Normativa/MEC n. 17, de 28 de dezembro de 2009. Dispõe sobre o mestrado profissional no âmbito da Fundação Coordenação de Aperfeiçoamento de Pessoal de Nível Superior - CAPES. Diário Oficial da União. Brasília (DF) 2009 dez. 29;Sec 1:20.

\author{
ENDEREÇO \\ Dartagnan Pinto Guedes \\ R. Ildefonso Werner, 177 \\ Condomínio Royal Golf \\ 86055-545 - Curitiba - PR - BRASIL \\ e-mail: darta@sercomtel.com.br
}

70 • Rev Bras Educ Fís Esporte, (São Paulo). 2017 Ago; 31(N esp):63-70. 